\title{
SYMPOSIUM
}

\section{Legal Issues in the Practice of Neurology and Neurosurgery}

\section{Participants:}

\author{
Brien G. Benoit, MD, MSc, FRCS(C) (Symposium chairman), Division of Neurosurgery, \\ Ottawa Civic Hospital \\ Judge T. David Marshall, MD, LLD, Executive Director, Canadian Judicial Center, Ottawa \\ Leslie P. Ivan, MD FRCS(C), Executive Committee, Canadian Medical Protective \\ Association \\ Pierre Forcier, MD, FRCS(C), Neurosurgeon, Assistant Director, Medical and \\ Rehabilitation Services, Regie de l'assurance automobile du Quebec
}

Kenneth G. Evans, BSc, BEd, LLB, Lawyer, Gowling, Strathy and Henderson, Ottawa.

General Counsel and Senior Legal Advisor, Canadian Medical Protective Association

Can. J. Neurol. Sci. 1990; 17:434-439

\section{INTRODUCTION}

Canadians are suing their doctors for malpractice, at three times the rate they were 15 years ago, and during that period awards to injured patients have quadrupled in size. Since the middle 1970's when the first medical malpractice "crisis" occurred in the United States, Canadian clinical neuroscientists have felt increasingly threatened by the prospect of a lawsuit for negligence. Since medicine is intrinsically a risk taking business, adverse outcomes are inevitable. Nevertheless, accusations of negligence and carelessness set out in a Statement of Claim causes considerable stress for the defendant physician, who frequently reacts with self-doubt, depression and aggressive behaviour. A "tort" is defined as a wrongful act, and the 4 elements comprising the tort of medical malpractice are: a breech of standard care, the breech was the proximate cause of the injury, the injury produced measurable damage, and it was foreseeable that the injury would have been less injurious to the patient if the caregiver had conducted a different course. In order to put these issues into current perspective, this symposium was convened as part of the XXIV Canadian Congress of Neurological Sciences, held in Ottawa June 17, 1989.

\section{Currenit Trends in Canadian Malpractice Law}

\section{Mr. Justice David Marshall}

Current trends in malpractice law have become a growing source of concern in Canada as we watch ourselves moving toward the American "crisis model" with regards malpractice litigation towards doctors. Every neuroscientist in clinical practice is more or less threatened by the possibility of being pursued in court, which is often seen as a malignant conspiracy by rapacious lawyers and ungrateful patients. However, the "pure" common law tort of medical negligence, is a reasonable social mechanism for compensating meritorious cases of true medical negligence, and ensuring a high level of medical competence. ${ }^{1}$ Consequently, it is both beneficial and desirable for the medical profession to preserve the common law right of the patient to sue his, or her doctor for perceived medical negligence.

\section{The "Classical" Malpractice Action}

The test for liability of a medical practitioner is that the plaintiff must prove, on a balance of probabilities, that the treatment of diagnosis rendered fell below the standards set by other ordinary prudent practitioners, under similar circumstances, and that this act injured the patient.

Several points require emphasis: nothing is demanded regarding results. Bad results without substandard care does not give rise to liability. Similarly, errors in judgment do not give rise to liability. If standard practice and ordinary prudence are applied, errors in judgment are not culpable. Doctors are not insurers, and do not guarantee successful treatment. The standard that the law says physicians must meet is the standard doctors set for themselves. It is not a standard of care set by lawyers or judges. The court does not try to second guess the doctor in cases of misadventure or bad result, but rather asks other doctors, the 
expert witnesses, what would an ordinarily prudent doctor have done. Consequently, the plaintiff will succeed only if he or she can prove, on the balance of probability, that the defendant doctor failed to live up to the standard that other doctors have set. ${ }^{2}$ Bad judgments of themselves, do not give rise to liability.

With regards the rules on informed consent, the standard is somewhat different, because the doctor can be held liable even though he/she did exercise care and prudence in diagnosis and treatment. ${ }^{1}$ Canadian courts follow the liberal democratic principle that every patient has the right to make his or her own decision regarding medical treatment. In order to make the decision, the patient is entitled to have full information of material risks of either undergoing or foregoing the proposed treatment. The physician is required to give the patient all the required information.

\section{Current Erosion of the Rule}

Legal rules do not operate in a vacuum. Rather, they operate in a very fluid and complex social matrix, where changes of every description are constantly taking place. The more obvious changes are; a more litigious populace, a weakened doctorpatient relationship, and society that is much more materialistic and consequently more inclined to sue for redress. Higher levels of education, higher expectations, more complex medical procedures, government ownership of hospitals, and funding of medical care, as well as legal aid, tend to exert pressure on the tort of medical negligence and have led to more claims against doctors.

There has been an erosion of limitation periods, which makes it difficult to calculate insurance liability. Memories and records fade with time. Courts have strained to lengthen limitation periods, in an attempt to assist people injured in the course of medical care. Damage awards have risen; it is common knowledge that doctors and hospitals are insured, and faced with a greatly disabled individual and with the high costs of home care, there is an inevitable straining by the court to find for the plaintiff. Courts are not immune to compassion and sympathy, even though they seek to apply to law in a dispassionate way.

\section{National Study - "Liability and Compensation Issues in Health Care"}

The findings and recommendations by a commission chaired by Dean Pritchard of the University of Toronto have not yet been finalized or published; it is expected that findings will include the following points:

1) there has been an escalation in liability to health care providers.

2) this increased liability occurred even though the law has not changed significantly.

3) medical malpractice litigation is very expensive - more than $50 \%$ of the costs go to the litigation and not to the injured party. 4) the threats of malpractice litigation raises the quality of health care.

5) only a small number of persons suffering avoidable medical injuries receive compensation.

6) litigation will continue to grow over the next decade or two in the absence of changes in our policies.

It is probable, that the Pritchard commission will recommend:

1) reform into the calculation and payment of damages, to include some form of periodic payment as opposed to lump sum awards. Litigation should be cheaper and faster.
2) the responsibilities of the hospital and other institutions should increase, thereby improving quality control and risk management programmes.

3) a compassionate society must find a way to compensate a greater number of medical injury victims, without further burdening the malpractice litigation system. This could be achicved by unfurling the welfare net and providing an available and accessible alternative.

I have some reservations and misgivings of these recommendations. A government compensation scheme would result in loss of autonomy and independence to the medical profession and loss to the public of the ability to pursue a proper claim for compensation. The costs of such a scheme would be almost intolerable, and would result in compensation for virtually all of the seriously diseased. With regards to increasing the responsibility of hospitals, it is difficult to envision how the institution can be made more liable, since it does or does not cause the injury through its regular practice. A shift towards institutional responsibility will affect the independence of the doctor vis-a-vis the institution that stands responsible. The hospital would begin making decisions, that are currently in the field of the medical professional. Doctors would become mere servants of the hospital. Both Dean Pritchard, and I. feel that the tort remedy should be maintained. I question that the profession can seek succor in a proposed "no fault scheme", nor by making the hospital more liable for the doctors who practice in them. The latter is a ruse, that would result in the government providing compensation by funding the hospitals. This is simply an increase in the social welfare net.

Finally, the tort system dispassionately applied as it was meant to be, with each case decided according to law, may well remain the best recourse for both doctor and patient. For the medical professional, freedom has its price; premiums may rise but by ridding ourselves of substandard practices and providing an efficient defence, the "classical" malpractice action may still be better than any alternative. ${ }^{3}$

\section{The Experts and Their Madical-Legal Reports}

\section{Dr. Pierre Forcier}

Obtaining a medical degree takes 5 years, and a specialist's certificate an additional 4 to 7 years. During that time, the student is working under the close supervision of experienced specialists, and the quality of his practice is constantly measured by the results obtained. However, when a "specialist" is asked to give a medical-legal opinion, he frequently will do so without any theoretical study, without specific training, and often after the most cursory inquiry as to the requirements. He thus becomes a fully qualified medico-legal "expert" created by himself!

The Regie de l'assurance automobile du Quebec provides compensation for the physical and psychic injuries, of all Quebec residents injured in a motor vehicle accident, without regard to fault. Over the past 10 years approximately 195,000 medical-legal opinions have been obtained from 425 specialists; $65 \%$ of them orthopedic surgeons, $13 \%$ neurosurgeons and neurologists, $5 \%$ psychiatrists and $4 \%$ from general surgeons and others. Many of these reports were legally unacceptable and it became obvious that most of the specialists that the Regie dealt with were unable to explain why a lump sum was paid to a victim after a period of salary indemnification. This sum is paid because there are permanent sequelae, and no return to the 
"statu quo ante". Permanent sequelae, give the right to compensation by way of a lump sum, whereas an injury in itself (or a diagnosis) does not.

In a review of 100 medical-legal reports randomly gathered within a single specialty representing the opinion of 10 specialists, several disturbing conclusions were drawn. Many specialists did not know the meaning of "medical proof", they did not know, that from unverified premises, a valid conclusion could only be reached by chance; they did not know the difference between "certain", "probable" and "likely"; they did not know the difference between objectivity and subjectivity; they were fond of unsubstantiated opinions; they did not know how to establish the relationship, the causal connection between an accident and an injury, and between the injury and their physical findings; they frequently treated medical-legal work as if it were only another "consultation", or as a second-class type of endeavor. Only 26 reports out of these 100 , could have been used before a court of law. Before writing his first medical-legal report, a medical specialist should have mastered the following principles:

1. The causal relation: Establishing the double causal connection accident-injury and injury-sequelae gives the victim a right to compensation. Many specialists recommend acceptation or refusal of this double relationship, based on feelings, impressions, or personal conviction, when there are no sound criteria to arrive at such a conclusion.

The specialist must consider the reality, nature and severity of the injury. For physical injuries there is usually a direct proportion between the severity of the traumatic event, and the injuries and sequelae. Minor injuries should not generate endless periods of incapacity, nor major sequelae. Allegations of injury must be verified and should not be taken for granted. Contemporary documents must be studied carefully. The medical evaluator must consider the mechanism of injury; a minor scalp injury does not cause epilepsy, nor does a cervical sprain cause an optic nerve stretch and a one month period of blindness! Some injuries are known to manifest themselves after some delay, but in most cases there will be no delay. In traumatology, the symptoms and signs do not take time to be readily perceived, and consequently a "whiplash" manifesting itself weeks or months after a trivial accident in which a knee was injured, is ludicrous! The term "after" indicates only a time relationship, not necessarily a causal relationship.

The continuing process of the injury usually speaks for itself. A lesion has become manifest immediately after the event, and persists being objectively symptomatic. A cascade of uninterrupted complications, one being the direct cause of the next, forms a continuing process which must be taken into consideration when establishing the causal link. The natural history of an injury must be considered in the context of causal connection. After 3 months, a trivial cervical sprain should be a thing of the past. How is it that symptoms are so numerous, and objective signs so absent? Is the patient developing psychiatric problems, is he becoming entangled in socio-legal difficulties? Is he simply malingering? Within a compensation setting, the natural history of an injury is very often distorted and unduly prolonged.

There must be simple correlation between the injuries observed at the time of the accident, and the measured sequelae.
For example, a fracture left forearm does not cause a right Dupuytren's contracture! In the case of a pre-existing condition, care must be used to help distinguish what sequelae are due to the accident, and what are unrelated to the event. An accident may cause a temporary aggravation of pre-existing condition, a permanent one.

The evaluator must untangle the causal link using the above criteria. A tie must hold together the link accident-injury-sequelae. If there is a breech of continuity, the causal relationship should be denied. Positive evidence is absolutely essential to a positive conclusion.

2. "Probable" vs "Possible" vs "Likely": Many medicallegal experts have found an easy way to resolve a dilemma by simply "giving the benefit of the doubt" to the claimant. A medical expert may not abrogate to himself the right of giving "the benefit of the doubt", which is reserved for a judge or jury according to the criminal code. A medical opinion must consider the weight of the probabilities at arriving at a conclusion. Many experts avoid responsibility by utilizing terms such as "possible", "compatible with", "likely", "plausible", etc. "Probable" applies to what is supported by evidence that is strong, but not conclusive; "possible" applies to what lies within the known limits of performance, attainment, nature of mode of existence of a thing or person, regardless of the chances for or against its actuality. Using "probable" one may conclude with some confidence but not from "possible". The term "likely" differs from "probable" in implying a more superficial, or more general grounds for judgment or belief. It implies a weaker meaning and does not allow the expert to draw a conclusion of probability.

3. Objectivity vs Subjectivity: This criteria could be summarized as "facts not words"! In daily medical practice genuine pain is most always supported by physical findings; why should it be different in medical-legal work! Rewarding the claimant because he knows how to complain, is not equity. The duty of the expert, is to establish that a deficit does indeed exist, being anatomical or physiological; without objective medical findings the expert should refrain from drawing conclusions. Mere complaints without physical or psychic substratum, should be treated as such and not be rewarded by the medical-legal expert. Another aspect of objectivity is impartiality. A medical-legal report should never be written to please the insured, or the insurer.

Based on my experience with the Regie, I am forced to conclude that basic medical-legal knowledge is lacking among many so called "experts". This lack of knowledge is extremely costly to society, the insured, and the insurer.

University and training programmes, should institute medical-legal options for interested specialists. A successful examination would be given the title of "medical-legal expert". More medical-legal societies should be created, in order to play an active role in teaching doctors, lawyers, and judges the principles of medical evaluation.

A medical-legal report, should not be considered as "merely another consultation" nor as an undesirable task.

No company, lawyer, or corporation should seek the opinion of a "specialist" unless he has proven that he has the basic knowledge and experience to give a valuable opinion.

Medical scientific meetings should always reserve a place on the programme for medical-legal topics. 
Pitfalls in the Practice of Neurology and NeUROSURGERY

\section{Dr. L.P. Ivan}

There are conflicting views regarding the existence of a "malpractice crisis" in Canada.4,5,6 In the United States, there has been an unprecedented escalation in the number of malpractice lawsuits, but our statistics show a levelling in the number of actions in the past 4 years from 906 to 873 . Nevertheless, during the past 3 years, legal fees and awards for damages in Canada have more than doubled. Between 1984 and 1988, legal fees increased from $\$ 7,420,571.00$ to $\$ 16,587,075.00$ and the awards for damages from $\$ 13,788,599.00$ to $\$ 25,390,306.00$.

Because of this rise in costs, the Canadian Medical Protective Association (CMPA) changed its fiscal policy to a "fully funded" basis in 1983, in order to create the necessary reserves required for multimillion dollar lawsuits. Although the number of legal actions against neuroscientists has not increased, it was imperative to increase membership fees in order to meet potential financial obligations (Table 1). Although neurosurgeons and neurologists did not create the critical rise in legal problems, and the rise in costs seems independent of performance, an easy calculation yiclds the reason why the CMPA required an increase in revenues. There are 160 neurosurgeons practicing in Canada, who will generate 160 times $\$ 12,000.00$ in fees for $\$ 1,920,000.00$ for the CMPA. But since this amount would pay only a fraction of one lost quadriplegic lawsuit, reserves must be available to maintain CMPA solvency. Because of the high costs associated with neurology/neurosurgery lawsuits, we must focus our attention on certain high risk areas.

\begin{tabular}{lccccccc}
\hline Table 1: CMPA Membership Fees 1983-1988 & & \\
\hline & $\mathbf{1 9 8 3}$ & $\mathbf{1 9 8 4}$ & $\mathbf{1 9 8 5}$ & $\mathbf{1 9 8 6}$ & 1987 & $\mathbf{1 9 8 8}$ \\
\hline Neurosurgeons & $\$ 500$ & $\$ 1,950$ & $\$ 2,900$ & $\$ 4,900$ & $\$ 8,250$ & $\$ 9,800$ \\
Neurologists & $\$ 500$ & $\$$ & 500 & $\$ 750$ & $\$ 900$ & $\$ 1,350$ & $\$ 1,750$ \\
\hline
\end{tabular}

In a 4 year period (1983-1987) 225 files were opened at the CMPA, in which either a neurologist or neurosurgeon was involved (Table 2). It seems, that every second neurosurgeon and every tenth neurologist is at risk from a medical-legal viewpoint. A total of 292 problems were identified in these 225 files, and $33 \%$ of the problems resulted in legal actions. As of 1987 , $78 \%$ of these files were still open and only $22 \%$ of these files were closed. In 26 of the 96 files, 1 or more neurologists and in 82 of the 96 files, 1 or more neurosurgeons were named as defendants. In some cases, both specialties were named. Twothirds of the problems were procedure-related, and $1 / 3$ were independent of surgery or diagnostic procedures. The majority of the

Table 2: Review of 225 CMPA Files Involving a Neurologist or Neurosurgeon (1983-1987)

\begin{tabular}{lrc}
\hline Description of Problem & No. & $\%$ \\
\hline Advice & 111 & $38 \%$ \\
Lawsuit & 96 & $33 \%$ \\
Threat & 39 & $13 \%$ \\
College Complaint & 30 & $10 \%$ \\
Inquest & 12 & $4 \%$ \\
Health Discipline Board & 4 & $1 \%$ \\
\hline Total Problems & 292 & $100 \%$ \\
\hline
\end{tabular}

Table 3: Non-Procedure-Related Problems Leading to Lawsuits

\begin{tabular}{lr}
\hline Delay in diagnosis & 13 \\
Failure to diagnose & 5 \\
Dissatisfaction with treatment & 7 \\
Problems with reports & 5 \\
Consent issues & 4 \\
Problems with medication & 5 \\
\hline Total & 39 \\
\hline
\end{tabular}

non-procedure related lawsuits related from a delay in diagnosis, or dissatisfaction with treatment (Table 3).

The 96 lawsuits related to poor outcome, are analysed in (Table 4). In $51 \%$ of the cases, it was a disastrous outcome that triggered the lawsuit, whereas in the remaining $49 \%$ the dissatisfaction often arose from minor problems. The relative frequency of clinical difficulties that required surgery and ended in lawsuits, is analysed in Table 5. The commonest anatomical region leading to medical-legal difficulties is the cervical spine. From a total of 20 cases, 12 were related to elective surgery, and 8 to treatment provided after an accident. The problems that arose from elective surgery on the cervical region are listed in Table 6. Fracture-dislocations of the cervical spine arising from management of these are common. Two cases of quadriplegia, one of quadriparesis, and one of hemiplegia, represented many million dollars in awards. A variety of unfavorable outcomes after lumbar disc surgery are listed on Table 7. Remaining discomfort, and a poorly informed consent, is a high risk situation. Major disability after disc surgery (paraplegia, encephalopathy) or a fatal complication, will inevitably result in a lawsuit.

\begin{tabular}{lrr}
\hline Table 4: Outcome in 96 Cases Leading to Lawsuits & \\
\hline \hline Death & 24 & $25 \%$ \\
Pain & 10 & $10 \%$ \\
Hemiplegia & 4 & \\
Quadriplegia & 4 & \\
Paraplegia & 3 & \\
Hemiparesis & 2 & \\
Neurological deficit & 2 & \\
Various dissatisfactions & 47 & $49 \%$ \\
\hline Total & 96 & \\
\hline
\end{tabular}

Table 5: Clinical Problems Requiring Surgery Which Ended in Lawsuits

\begin{tabular}{lr}
\hline \hline Cervical disc or injury & 20 \\
Lumbar disc problem & 12 \\
Aneurysm \& AVM & 8 \\
Brain abscess/tumor/infection & 7 \\
Pain & 7 \\
Head injuries & 5 \\
Peripheral nerves & 5 \\
Miscellaneous & 7 \\
\hline Total & 71 \\
\hline
\end{tabular}

Our analysis of CMPA files, confirms that the commonest anatomical area related to lawsuits is the cervical spine (20 cases) followed by the lumbar spine ( 12 cases) followed by all intracranial lesions, whether vascular, neoplastic, or due to other causes. Considering the triggering causes of a lawsuit clinical neuroscientists became liable when the diagnosis was missed or delayed, or there was surgical error with a less than ideal outcome. The risks can be expressed in the following equation:

Angry Patient + Unfavorable Outcome = Lawsuit 


\section{Table 6: Problems Arising From Elective Surgery on the Cervical Spine}

1. Discectomy - wrong level

2. Spinal fusion - postop. neur. deficit

3. Spinal stenosis - postop. quadriparesis

4. Laminectomy - cord damage during decompression

5. Laminectomy $\mathrm{Cl}-\mathrm{C} 2-\mathrm{C} 3$ - complications

6. Anterior discectomy, 2 levels - complications

7. Cervical discectomy/Cloward/- quadriparesis

8. Cervical discectomy - prolonged disability postop.

9. Cloward procedure - vocal cord paralysis

10. Anterior fusion - Brown-Sequard syndrome

11. Posterior discectomy $\mathrm{C} 6 / 7$ - quadriparesis

12. Decompressive laminectomy- increased deficit

Certain preventive measures may be applied to deal with high risk situations, and several texts now deal with medicallegal guidelines, ${ }^{7}$ helping to sharpen the focus of these areas. In evaluating his neurosurgical risk, the clinical neuroscientist must consider the following:

1) A high professional standard is a good preventative measure against the lawsuit.

2) A good doctor-patient relationship, and good communication is the best preventive measure against the emergence of an angry patient or hostile relatives.

3) The consent must be informed, allowing the patient or nearest relative to understand the natural course of the disease, the result and material risk of the suggested treatment, the name of the person who administers this treatment and the available alternative of the proposed management plan. The modern concept of "informed consent" can be traced back to a neurosurgical case, ${ }^{8}$ when a carotid endarterectomy resulted in hemiplegia. This case resulted in a lost lawsuit, and also made legal history in Canada.

4) Good documentation does not prevent a lawsuit, but accurate and detailed notes can help the defence to establish the facts and prove a high professional standard.

Unfortunately, bad results can occur even when the highest standard of care is applied, but if there is a truly informed consent and good quality documentation, and a high professional attitude is maintained, even a disastrous outcome can be defended. If, on the other hand, the quality of care is borderline or substandard, and if the documentation is poor (as has occurred in 10 to $15 \%$ of cases) defence becomes very difficult and may not even be possible.

\section{The Physician as an Expert, Consultant or Defendant in a MaLpRaCtice ACtion}

\section{Mr. K.G. Evans}

In any malpractice action, whatever the ultimate outcome, the expert consultant and the defendant doctor exert the most significant influence on the result. The majority of actions involve the allegation that the defendant physician did not exercise a reasonable and acceptable standard of care and skill which would normally be expected of a peer with similar experience and training. As a result, harm or injury is alleged to have been caused to the patient. These allegations extend not only to positive acts, but also to omissions, and it is this latter category, and alleged failure to adequately attend, diagnose, refer or treat the patient, which constitutes a large majority of legal actions.
Table 7: Unfavourable Outcomes Following Surgery to Lumbar Disc or Spinal Stenosis

1. Lack of consent for surgery

2. Surgery with complications

3. Continued back pain after discectomy

4. Cautery burn during discectomy

5. Post-laminectomy death

6. L4 disc protrusion missed at laminectomy

7. Chymopapain - paraplegia + encephalopathy

8. Injury to iliac artery - death

9. Back pain - allegation of negligence

10. Disectomy - dissatisfaction with result

11. Decompression laminectomy - back pain postop.

12. Laminectomy - paraplegia

\section{The Expert Consultant}

In determining whether a physician has been negligent, the appropriate measure is not a standard of perfection, but rather the more moderate level of care which could reasonably be expected of a prudent colleague in similar circumstances. In this context, the expert consultant it called to advise the Court, in order to establish the standards ordinarily met by the defendant doctor's peers. All physicians should consider carefully any reasonable request to act as an expert consultant for a patient. The "conspiracy of silence" theory is often expounded by plaintiffs counsel, who have demonstrated little initiative in obtaining independent expert opinion. Often, these lawyers are not prepared to accept that the inability to obtain a favorable expert opinion is more a reflection of lack of legal merit to the claim than an alleged conspiracy of silence. The opinion of a competent, objective expert, may, in fact, discourage the pursuit of an unwarranted legal action. However, on the defence side, we are increasingly concerned about the emergence of "the counsel of perfection" being advocated by some expert witnesses, who are called to give evidence on behalf of the plaintiff. These expert consultants, seem to apply a textbook standard in assessing the role of the defendant doctor, a standard which is impossible to adhere to on all occasions. Our perception is that what in earlier years might have been seen as an "error in judgement" now may be designated "negligent", simply because of the very high standard applied by certain expert consultants, when testifying for the plaintiff. Some of the reasons why this "high standard" is being increasingly applied are:

1) the term "expert" may induce consultants to prepare so thoroughly, and become so knowledgeable that they lose sight of the more moderate level of skill and knowledge generally held by their colleagues.

2) the experts may be motivated by pride and fear that they may face criticism, unless they advocate an optimum standard of care and skill.

3) the expert consultant may be on a personal crusade to upgrade the standards of practice within a certain specialty.

4) certain consultants become "hired guns" who realize that future retainers depend on results, and are therefore prepared to slant their evidence accordingly.

5) the failure of many expert consultants to appreciate and understand their role in the legal process.

It bears repeating that the function of the expert consultant is to advise the Court as to the proper standard of care against which the defendant doctor is to be judged. The responsibilities of an expert consultant include: 
1) To consider whether or not he is appropriately qualified to provide the necessary opinion, in regard to the circumstances of the case. However, leading specialists are not the only ones qualified to act as expert consultants: an experienced general practitioner, is often best qualified to speak of the work of a fellow general practitioner.

2) The expert should obtain the review carefully, at the very outset all of the available medical material. He should insist on seeing all of the hospital and other medical records, and should have access to the transcripts of the Examinations for Discovery and the report of other expert consultants.

3) The expert should establish whether the defendant doctor exercised the appropriate standard of care in the circumstances of the case. He must be guided by personal experience, and what is perceived to be the usual or customary practice of his colleagues in similar circumstances. Allowance must always be made for the advantage of reviewing facts in retrospect. In guarding against applying too high a standard, the expert consultant should remember that medicine is not an exact science and therefore the physician cannot guarantee a satisfactory result. Untoward results may occur even when the highest possible degree of skill and care have been applied.

4) The expert must avoid any attempt to portray himself as an advocate of one party or the other. His duty is to assist the Court, through an expression of an opinion within the limits of his medical expertise.

\section{Defendant Doctor}

The defendant doctor must be prepared to devote considerable time and effort in the preparation of the defence since the legal claim is against the doctor personally, and it is his/her reputation and stature which are at stake. The defendant's responsibilities include:

1) To cooperate fully with legal counsel assigned to take charge of the defence. The physician should have faith and place reliance upon advice and legal recommendations.

2) To assist in the accumulation of all relevant office and medical records. The defendant must never change, amend, add, delete, rewrite, modify, improve or otherwise alter medical records related to the patient. Any alteration of the medical record after the fact could only serve to destroy the credibility of the physician, not only with reference to the accuracy of the medical record, but on other issues as well.

3) To study the medical records thoroughly and become familiar with all of the facts and information contained therein. There will be a number of meetings with defence counsel as litigation proceeds and preparation is of the utmost importance, for evidence given by a physician at Examination for Discovery, can, and will, be used against him at the time of any trial. The physician should carefully study the transcript of the Discovery and be prepared to answer the same questions, in the same manner, during the course of any subsequent trial.
4) An intense preparation for the trial of the action. The demeanor and impression which the defendant doctor leaves with the trial judge or members of the jury, is one of the most important factors in the trial process. This relates to the credibility that will be accorded the evidence of the physician, and therefore the outcome of trial. The following recommendations can be made to any physician testifying in a trial, either ats expert consultant or defendant:

- speak to the judge when answering questions.

- answer questions in a straight forward manner and do not volunteer additional information in the course of cross examination by the other lawyer.

- fully understand the question before answering.

- avoid anger at opposing legal counsel.

- do not become an advocate; simply answer questions fairly and honestly.

- do not acknowledge familiarity with medical texts or literature, if such is not the case.

- clearly indicate questions which are beyond your area of expertise. This enhances your credibility, generally.

- have a good command of relevant documentation, including dates and times mentioned in medical records.

- speak in a slow, deliberate manner.

- translate medical terms into language, for the convenience of the judge and jury, without appearing to be condescending.

- avoid attempts to guess or speculate.

- address the trial judge as "my Lord" or "my Lady".

Clearly understanding the role and responsibility of expert or defendant, will render the legal process more tolerable, and improve the likelihood of a just outcome.

\section{REFERENCES}

1. Marshall TD. The Physician and Canadian Law. Toronto: Carswell Co. Ltd. 1979

2. Dickson B. Law and medicine: conflict or collaboration? J Neurosurg 1988; 69: 319-325.

3. Marshall TD. Malpractice claims: no fault is no answer. Can Med Assoc J 1988; 139: 426-427.

4. Dickens BM. The medical malpractice problem in the United States and Canada. Transplantation/implantation today. 1988; 4: 31-36.

5. Geekie DA, Oscapella EL. CMA issues call for action to deal with malpractice insurance "crisis". Can Med Assoc J 1986: 135: 145-149.

6. Tovee EB. The changing face of malpractice as it involves the neurosciences in Canada: In: Morley TP ed. Moral, ethical, and legal issues in the neurosciences, Springfield, III.: Charles C. Thomas, 1981: 38-41.

7. Brooten KE, Chapman S. Malpractice, a guide to avoidance and treatment. NY: Grune \& Stratton, Inc. Harcourt Brace Jovanovich, Publishers. 1987.

8. Reible v. Vughes (1980), 114 D.L.R. (3d) I (S.C.C.), quoted by Dickens (see ref. 4).

9. Messenger $O$. Risk management in the hospital: medical staff must be involved. Can Med Assoc J 1988; 139: 994-996. 